Acta Crystallographica Section E

\section{Structure Reports}

Online

ISSN 1600-5368

S. Naveen, ${ }^{a}$ T. D. Venu, ${ }^{b}$ S. Shashikanth, ${ }^{\text {b }}$ M. A. Sridhar ${ }^{\mathrm{a} *}$ and J. Shashidhara Prasad ${ }^{a}$

${ }^{a}$ Department of Studies in Physics, Mansagangotri, University of Mysore, Mysore 570 006, India, and ${ }^{\mathbf{b}}$ Department of Studies in Chemistry, Mansagangotri, University of Mysore, Mysore 570 006, India

Correspondence e-mail:

mas@physics.uni-mysore.ac.in

\section{Key indicators}

Single-crystal X-ray study

$T=295 \mathrm{~K}$

Mean $\sigma(\mathrm{C}-\mathrm{C})=0.004 \AA$

$R$ factor $=0.046$

$w R$ factor $=0.153$

Data-to-parameter ratio $=12.2$

For details of how these key indicators were automatically derived from the article, see http://journals.iucr.org/e.

\title{
(4-Chlorophenyl)(2-hydroxy-5-methylphenyl)- methanone
}

In the title compound, $\mathrm{C}_{14} \mathrm{H}_{11} \mathrm{ClO}_{2}$, the dihedral angle between the two aromatic rings is $51.98(11)^{\circ}$. The molecular conformation is stabilized by a strong intramolecular $\mathrm{O}-$ H. . O hydrogen bond.

\section{Comment}

Benzophenones and related compounds have a wide variety of applications, in particular as biologically active compounds, which exhibit anti-inflammatory (Khanum et al., 2004), antifungal, antibacterial and anticancer activities. They are also used as core steroid sulfatase (STS) inhibitors with IC50 values between 5 and $7 \mu M$. They are extensively used as sunscreen lotions for UVA protection. Owing to the importance of various substituents on the benzophenone nucleus, the title compound, (I), was synthesized and its crystal structure is reported here.<smiles>Cc1ccc(O)c(C(=O)c2ccc(Cl)cc2)c1</smiles>

The molecule of (I) is non-planar (Fig. 1). The dihedral angle between the two aromatic rings is $51.98(11)^{\circ}$; this compares with the corresponding value of $57.37(12)^{\circ}$ observed for (3-chlorophenyl)(2-hydroxy-5-methylphenyl)methanone, (II) (Khanum et al., 2005). The C4-C5-C7$\mathrm{O} 16$ and $\mathrm{O} 16-\mathrm{C} 7-\mathrm{C} 8-\mathrm{C} 9$ torsion angles are -12.1 (3) and $-40.8(3)^{\circ}$, respectively, indicating that the carbonyl group is almost coplanar with the 2-hydroxy-5-methylphenyl plane but is considerably more displaced from the 4-chlorophenyl plane. Bond lengths and angles have normal values and are comparable to those reported for (II). The molecular conformation is stabilized by a strong intramolecular $\mathrm{O}-$ H...O hydrogen bond (Table 1). A detailed study of the biological activity of (I) is underway.

\section{Experimental}

4-Chlorophenyl-4-chlorobenzoate $(0.039 \mathrm{~mol}, 10 \mathrm{~g})$ was thoroughly mixed with montmorillonite $\mathrm{K}-10$ clay in the solid state, using a vortex mixer and subjected to microwave irradiation at $40 \%$ power for $5 \mathrm{~min}$. The completion of the reaction was monitored by thin layer chromatography and the product was extracted into dichloro-
Received 10 April 2006 Accepted 15 April 2006 


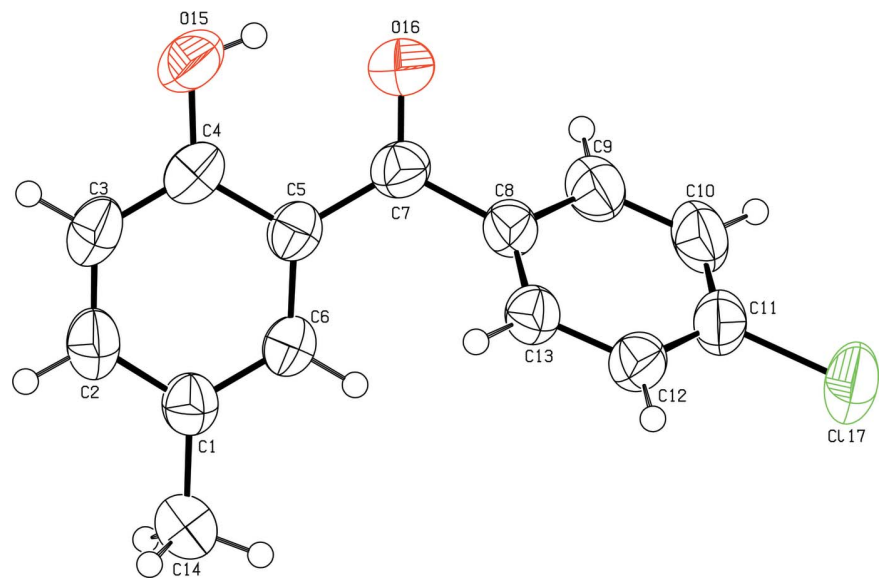

Figure 1

View of (I), with $50 \%$ probability displacement ellipsoids.

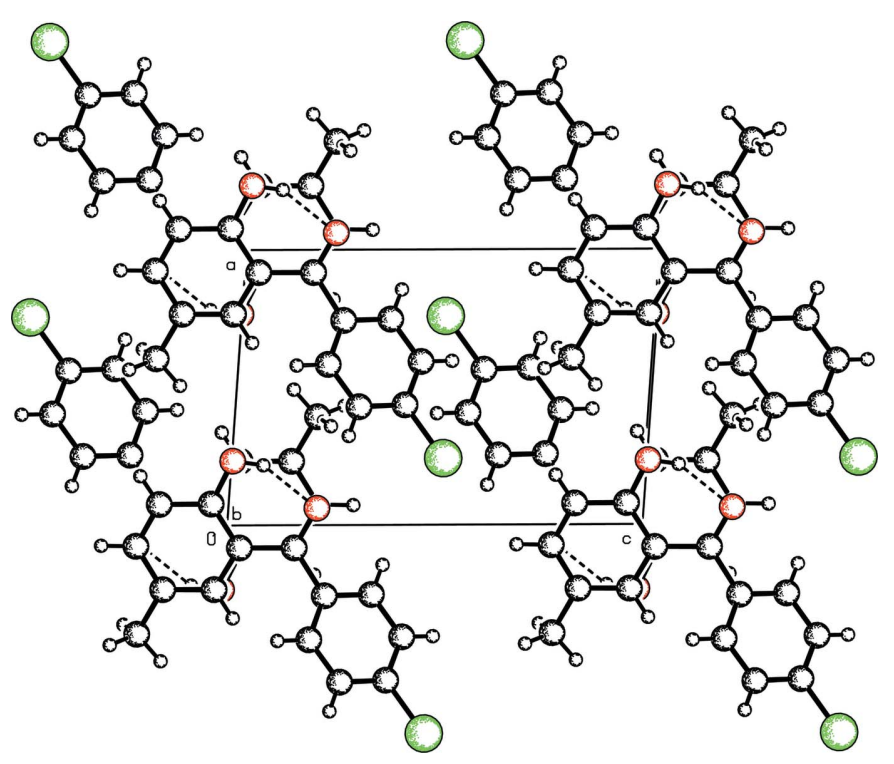

Figure 2

The crystal packing in (I), viewed down the $b$ axis. Dashed lines indicate hydrogen bonds.

methane. The organic layer was dried over anhydrous sodium sulfate and evaporated to dryness, giving a crude solid, which, on recrystallization with ethanol, gave yellow crystals (yield 87\%; m.p. 359 K).

\section{Crystal data}

$\mathrm{C}_{14} \mathrm{H}_{11} \mathrm{ClO}_{2}$

$M_{r}=246.68$

Triclinic, $P \overline{1}$

$a=7.362(8) \AA$

$b=7.440(10) \AA$

$c=11.001$ (14) $\AA$

$\alpha=88.144$ (5)

$\beta=85.622(9)^{\circ}$

$\gamma=82.831(8)^{\circ}$

\section{Data collection}

MacScience DIPLabo 32001

diffractometer

$\omega$ scans

Absorption correction: none

3083 measured reflections

\section{Refinement}

Refinement on $F^{2}$

$R\left[F^{2}>2 \sigma\left(F^{2}\right)\right]=0.046$

$w R\left(F^{2}\right)=0.153$

$S=1.08$

1898 reflections

156 parameters

$\mathrm{H}$-atom parameters constrained
1898 independent reflections 1610 reflections with $I>2 \sigma(I)$ $R_{\text {int }}=0.023$

$\theta_{\max }=25.0^{\circ}$

Table 1

Hydrogen-bond geometry $\left(\AA{ }^{\circ}\right)$.

\begin{tabular}{lllll}
\hline$D-\mathrm{H} \cdots A$ & $D-\mathrm{H}$ & $\mathrm{H} \cdots A$ & $D \cdots A$ & $D-\mathrm{H} \cdots A$ \\
\hline $\mathrm{O} 15-\mathrm{H} 15 \cdots \mathrm{O} 16$ & 0.82 & 1.85 & $2.569(4)$ & 145 \\
\hline
\end{tabular}

$\mathrm{H}$ atoms were placed at idealized positions and allowed to ride on their parent atoms with $\mathrm{C}-\mathrm{H}$ distances in the range $0.93-0.96 \AA$ and $\mathrm{O}-\mathrm{H}=0.82 \AA ; U_{\text {iso }}(\mathrm{H})$ values were set equal to $1.2 U_{\text {eq }}(\mathrm{C})$, or $1.5 U_{\text {eq }}(\mathrm{C}, \mathrm{O})$ for methyl and $\mathrm{OH}$ groups.

Data collection: XPRESS (MacScience, 2002); cell refinement: SCALEPACK (Otwinowski \& Minor, 1997); data reduction: SCALEPACK and DENZO (Otwinowski \& Minor, 1997); program(s) used to solve structure: SHELXS97 (Sheldrick, 1997); program(s) used to refine structure: SHELXL97 (Sheldrick, 1997); molecular graphics: PLATON (Spek, 2003) and ORTEPII (Johnson, 1976); software used to prepare material for publication: SHELXL97.

We thank the DST, Government of India, for financial assistance under the project SP/I2/FOO/93.

\section{References}

Johnson, C. K. (1976). ORTEPII. Report ORNL-5138. Oak Ridge National Laboratory, Tennessee, USA

Khanum, S. A., Mahendra, M., Shashikanth, S., Doreswamy, B. H., Sridhar, M. A. \& Shashidhara Prasad, J. (2005). Acta Cryst. E61, o3615-o3617.

Khanum, S. A., Venu, T. D., Shashikanth, S. \& Firdouse, A. (2004). Biol. Org. Med. Chem. Lett. 12, 2093-2095.

MacScience (2002). XPRESS. MacScience Co. Ltd, Yokohama, Japan.

Otwinowski, Z. \& Minor, W. (1997). Methods in Enzymology, Vol. 276, Macromolecular Crystallography, Part A, edited by C. W. Carter Jr \& R. M. Sweet, pp. 307-326. New York: Academic Press.

Sheldrick, G. M. (1997). SHELXS97 and SHELXL97. University of Göttingen, Germany.

Spek, A. L. (2003). J. Appl. Cryst. 36, 7-13. 